\title{
Aminoglycosides Resistance among Acinetobacter baumannii Complex Isolated from Hospital Acquired Blood Stream Infections
}

\author{
Ghada El-Saeed Mashaly* \\ Medical Microbiology and Immunology Department, Faculty of Medicine, \\ Mansoura University, Egypt \\ *Corresponding author
}

\section{A B S T R A C T}

\section{Keywords \\ Acinetobacter \\ baumannii, \\ Resistance, \\ Aminoglycosides, \\ Bloodstream \\ infections, \\ Aminoglycosides \\ modifying enzymes, \\ Antibiotic \\ combination.}

\section{Article Info}

Accepted:

10 September 2017

Available Online:

10 November 2017
Resistant Acinetobacter baumannii complex associated with bloodstream infections is a major concern in hospitalized patients. Aminoglycosides resistance in Acinetobacter baumannii complex is mainly caused by enzymatic modification of aminoglycosides. This study was designed to identify the prevalence of aminoglycosides resistance and its association with aminoglycosides modifying enzymes (AMEs) genes and armA gene for 16S rRNA methylase among Acinetobacter baumannii complex causing bloodstream infections in patients of Mansoura University Hospitals (MUHs). Also, to evaluate the effect of aminglycosides combinations on extensively resistant strains to all tested agents. Blood culture samples were collected from patients with signs and symptoms of blood stream infections. Acinetobacter baumannii complex were identified by API 20 NE. Antibiotic susceptibilities testing were performed by disc diffusion method. Activity of amikacin and gentamicin was evaluated in vitro in combination with ciprofloxacin and imipenem against resistant strains of Acinetobacter baumannii complex to all tested antibiotics using checkerboard titration method and the fractional inhibitory concentration index (FICI) was calculated for each combination. Resistant Acinetobacter baumannii

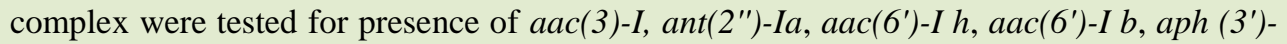
V1 AME genes and armA gene for 16S rRNA methylase using PCR. A total of 67 Acinetobacter baumannii complex isolates were collected during the period of the study. Forty-one isolates $(61.2 \%)$ were resistant to gentamicin and/ or amikacin. There were 15 isolates resistant to all tested antibiotics agents. Amikacin combination with ciprofloxacin and imipenem showed the highest synergistic effect against 40\%, 33.3\% respectively of these extensively drug resistant $A$. baumannii complex isolates. Combination of gentamicin-ciprofloxacin and gentamicin-imipenem each showed synergistic effect against $26.7 \%$ of these isolates. The most commonly encountered AME genes were $a a c\left(6^{\prime}\right)-I b$ and $\operatorname{aac}(3)-I$ (70.7\% and $65.8 \%$ respectively). ArmA $16 \mathrm{~S}$ rRNA methylase gene was encountered in $56.1 \%$ of resistant strains. The most prevalent gene profile was aac(3)- $I+$ $a a c\left(6^{\prime}\right)-I b+\operatorname{ant}\left(2^{\prime \prime}\right)-I a+\operatorname{armA}$ detected in $31.7 \%$ of resistant isolates. The extensively resistant strains mostly express the gene pattern $\operatorname{aac}(3)-I+\operatorname{aac}\left(6^{\prime}\right)-I b+\operatorname{ant}\left(2^{\prime \prime}\right)-I a+\operatorname{armA}$ $(6 / 15)$. This study concluded that aminoglycosides modifying enzymes are widespread in aminoglycosides resistant $A$. baumannii complex causing bloodstream infections. Combination therapy including amikacin and gentamicin with ciprofloxacin and imipenem can be used as for treatment of severe resistant A. baumannii blood stream infection. 


\section{Introduction}

Acinetobacter baumannii is an important hospital acquired pathogen. Multi and extensively antibiotic resistance stains emerged and widely distributed all over the world with extensive use of broad spectrum antibiotics (Hou et al., 2012). Acinetobacter baumannii complex (Acinetobacter calcoaceticus- Acinetobacter baumannii) complex composed of A. baumannii (genospecies 2), A. pittii (formerly known as Acinetobacter genospecies 3), and A. nosocomialis (formerly known as Acinetobacter genospecies 13TU). They are genetically and phenotypically similar to $A$. calcoaceticu (Acinetobacter genospecies 1) and hence are grouped in the so called Acinetobacter calcoaceticus-Acinetobacter baumannii complex (Ko et al., 2008; Nemec et al., 2011).

Aminoglycosides is a bactericidal group of antibiotics that have a vital role in treatment of serious Gram negative bacterial infections like blood stream infections (BSIs). However, many studies reported development of aminoglycoside resistance in Acinetobacter baumannii (Potron et al., 2015; Poole, 2005). Resistance to aminoglycosides is mediated by several mechanisms including aminoglycoside modifying enzymes (AMEs), efflux pump, 16S rRNA methylation and restricted bacterial membrane permeability to aminoglycosides agents. The production of AMEs and 16S rRNA methylase are the major mechanisms responsible for clinical resistance of Acinetobacter baumannii complex to aminoglycosides (Yadegar et al., 2009; Shaw et al., 1993).

Aminoglycoside-modifying enzymes are classified into three categories according to their action; acetyltransferase (AACs) which cause acetylating of free hydroxyl group. The most important genes encode this enzyme are include $a a c(3)-I$, and $a a c\left(6^{\prime}\right)-I b$. Second is phosphotransferase (APH) whose genes include $\operatorname{aph}\left(3^{\prime}\right) \mathrm{Vl}$. It causes phosphorylation of the free hydroxyl group. Third, the nucleotide transferase (ANT) which is also known as adenosine transferase (AAD), includes $\operatorname{ant}(3 ")-I$ and $\operatorname{ant}(2 ")-I$, which can lead to nucleosidation of free hydroxyl groups. 16S rRNA methylase is another mechanism in aminoglycosides resistance (Nemec et al., 2004).

Empirical combination antibiotic therapy is suggested as a potential option for treatment of severe infections caused by Gram negative bacteria. Combination is mainly of concern in infections caused by bacteria with high rates of resistance like Acinetobacter baumannii. Combination therapy should contain bactericidal broad spectrum antibiotics like aminoglycoside, beta-lactam and fluoroquinolone (Paul et al., 2014; Tamma et al., 2012).

The objectives of this study were to identify the prevalence of aminoglycosides resistance among isolates of Acinetobacter baumannii complex causing BSIs, to assess the possible synergistic effect of aminoglycosides drugs combinations with imipenem and ciprofloxacin against resistant Acinetobacter baumannii complex strains and detection of AMEs and 16S rRNA methylase genes associated with aminoglycosides resistance in these isolates.

\section{Materials and Methods}

This study was conducted on patients who have BSIs in Mansoura university hospitals for a period of 2 years extending from March 2015 to March 2017. Blood samples were collected from patients with suspected BSIs according to CDC criteria (Horan et al., 2008). Acinetobacter baumannii complex was identified by routine microbiological methods 
and API 20 NE (bioMérieux) which was performed according to the manufacture instructions (Koneman et al., 1997).

Antibiotic sensitivity testing was done by disc diffusion method according to the guidelines proposed by the Clinical Laboratory Standard Institute (CLSI, 2015) for Acinetobacter baumannii.

\section{Synergy testing}

Evaluation of the effect of aminoglycoside agents (gentamicin and amikacin) combinations with ciprofloxacin and imipenem on extensively resistant strains to all tested antibiotics was estimated by the checkerboard titration method (Lorian, 2005).

The MICs of individual drugs (imipenem, amikacin, gentamicin and ciprofloxacin) were estimated using broth microdilution method.

The MICs of aminoglycosides antibiotics (gentamicin and amikacin), imipenem and ciprofloxacin in combinations were estimated. Determination of MICs was done using the broth microdilution technique as recommended by the CLSI (2015).

The fractional inhibitory concentration index (FICI) was calculated for each antibiotic in each combination by using the following formula:

FICA=MIC of drug A in combination/MIC of drug A alone

FICB=MIC of drug B in combination/MIC of drug $\mathrm{B}$ alone

\section{$\mathrm{FICI}=\mathrm{FICA}+\mathrm{FICB}$}

FICI were interpreted as follows: $\leq 0.5$ Synergy, >0.5-1 (Additive effect), $>1<4$ (Indifferent), and $\geq 4$ Antagonism.

\section{Molecular identification of aminoglycosides resistance genes}

Bacterial DNA was extracted using QIAamp DNA extraction kits according to the manufacture instructions. PCR was performed according to the protocol described before (Van de Klundert et al., 1993; Shaw et al., 1993; Maynard et al., 2003; Díaz et al., 2004; Nie et al., 2014). Primers used are described in table 1.

\section{Statistical methods}

Descriptive data were presented in the form of number and parentages.

\section{Results and Discussion}

Aminoglycosides are important class of broad spectrum antibiotics that enter in treatment of severe life threatening infections as BSIs. They are used mainly in treatment of Gram negative bacterial infections. They are used also in treatment of Gram positive bacterial infections and Mycobacterium tuberculosis in combination with other antibacterial agents (Yao et al., 2007; Brossier et al., 2010). The growing problem of antibiotic resistance in $A$. baumannii complex has been worldwide concerns as it causes failure in treatment of severe infections (Hou et al., 2012; Potron et al., 2015).

In the present study, a total of 67 isolates of Acinetobacter baumannii complex were detected from bloodstream infections during the period of study. Most of the collected isolates were from neonatal and pediatric ICUs figure (1). Antibiotic susceptibilities to different antibiotics were determined by disc diffusion method according to CLSI recommendations (2015). All isolates were resistant to $2^{\text {nd }}$ generation cephalosprine agent (cefuraxime). Resistance to cefotaxime and imipenem were $(92.5 \%)$ and $(71.5 \%)$ 
respectively. Resistance to ciprofloxacin was $(74.6 \%)$. A total of $41(61.2 \%)$ isolates were resistant to one or more aminoglycosides agents. Thirty one $(46.3 \%)$ isolates were resistant to gentamicin and 24 isolates (35.8) were resistant to amikacin figure (2). Fifteen isolates $(22.4 \%)$ isolates showed co-resistance to amikacin and gentamicin. These isolates were resistant to all tested antibiotic agents

This high resistance to $3^{\text {rd }}$ generations cepahlosprins, imipenem and ciprofloxacin agrees with most of the previous studies like Lee et al., (2011) and Gao et al., (2017). However their findings regarding aminoglycosides resistance is lower than that of the present study. Also, aminoglycosides resistance in the current study is lower than finding of Kishii et al., (2014).

The higher rate of resistance to imipenem compared to aminoglycoside agents in this study may be due to the wide use of imipenem as an empirical therapy in bloodstream infections compared to aminoglycosides agents. In addition, the current study did not differentiate the susceptibilities of the different species of $A$. baumannii complex. A. baumannii (genospecies 2) is of higher resistance compared to other members of the complex.

\section{Effects of aminoglycosides combinations}

In the present study, the checkerboard titration method was used to evaluate the possible synergistic effect of aminoglycosides combinations with ciprofloxacin and imipenem to overcome resistance in $A$. baumannii complex.

Fifteen (15/41) (36.6\%) isolates of extensively drug resistant Acinetobacter baumannii complex (Magiorakos et al., 2012) were resistant to both aminoglycosides agents and to all tested antibiotics. The checkerboard titration method was performed against these resistant isolates. The MICs of gentamicin and amikacin were determined before and after combination with ciprofloxacin and imipenem and the FIC was calculated for each drug. The FICI was calculated for each drug combination (gentamicin with ciprofloxacin, gentamicin with imipenem, amikacin with ciprofloxacin and amikacin with imipenem).

The most effective aminglycoside combinations were amikacin-ciprofloxacin followed by amikacin-imipenem, they showed synergistic effect against 40\% (6\15) and $33.3 \%$ (5\15) respectively of extensively drug resistant $A$. baumannii complex isolates. They showed additive effect against $46.7 \%$ (7\15) and $53.3 \%$ (8\15) of the isolates respectively. Each of gentamicin-ciprofloxacin and gentamicin-imipenem showed synergistic effect against $26.7 \%$ (4\15) of extensively drug resistant $A$. baumannii isolates table (2). Antagonistic effect was not detected in any of the tested combinations.

These results are matched with previous reports (Yadav et al., 2015; Yadav et al., 2016). The exact mechanism for synergism is not known. However, synergism of imipenem could be explained by increased cell permeability and bacterial aminoglycosides uptake by cell wall synthesis inhibitors increasing their intracellular concentrations (Vakulenko and Mobashery, 2003). However the use of these combinations is limited by increased side effects.

So, these antibiotic combinations should used only in resistant cases when its benefits mostly outweigh the risks of increased side effects. Application of infection control policies is critical to reduce the problem of bacterial resistance, especially in countries where empirical antibiotic use is wide without prescription or culture sensitivity testing. 
Table.1 Primers used for detection of AMEs genes and 16S rRNA methylase

\begin{tabular}{|l|l|l|}
\hline Gene & Primer & Amplicone size \\
\hline Aminoglycoside modifying enzymes & $372 \mathrm{bp}$ \\
\hline aac(3)-I & $\begin{array}{l}\text { F: 5' GACATAAGCCTGTTCGGTT3' } \\
\text { R: 5'-CTCCGAACTCACGACCGA3' }\end{array}$ & $404 \mathrm{bp}$ \\
\hline ant(2')-Ia & $\begin{array}{l}\text { F: 5'-ATCTGCCGCTCTGGAT3' } \\
\text { R: 5'-CGAGCCTGTAGGACT3' }\end{array}$ & $407 \mathrm{bp}$ \\
\hline aac(6')-I $h$ & $\begin{array}{l}\text { F: 5'-TGCCGATATCTGAATC3' } \\
\text { R: 5'-ACACCACACGTTCAG3' }\end{array}$ & $395 \mathrm{bp}$ \\
\hline aac(6')-I b & $\begin{array}{l}\text { F: 5'-TATGAGTGGCTAAATCGAT3' } \\
\text { R: 5'-CCCGCTTTCTCGTAGCA3' }\end{array}$ & $716 \mathrm{bp}$ \\
\hline aph (3')-VI & $\begin{array}{l}\text { F: 5'-CGGAAACAGCGTTTTAGA3' } \\
\text { R: 5'-TTCCTTTTGTCAGGTC3' }\end{array}$ \\
\hline 16 S rRNA methylase gene & $\begin{array}{l}\text { F: 5'-ATTCTGCCTATCCTAATTGG-3' } \\
\text { R: 5'-ACCTATACTTTATCGTCGTC-3' }\end{array}$ & $315 \mathrm{bp}$ \\
\hline \multicolumn{2}{|l|}{ armA }
\end{tabular}

Table.2 Effects of gentamicin and amikacin drugs combinations on extensively drug resistant Acinetobacter baumannii complex

\begin{tabular}{|l|l|l|l|l|}
\hline & $\begin{array}{l}\text { Gentamicin- } \\
\text { ciprofloxacin }\end{array}$ & $\begin{array}{l}\text { Gentamicin- } \\
\text { imipenem }\end{array}$ & $\begin{array}{l}\text { Amikacin- } \\
\text { ciprofloxacin }\end{array}$ & $\begin{array}{l}\text { Amikacin-- } \\
\text { imipenem }\end{array}$ \\
\hline$\leq 0.5$ Synergism & $4(26.7)$ & $4(26.7)$ & $6(40)$ & $5(33.3)$ \\
\hline $\begin{array}{l}>0.5-1 \\
(\text { Additive })\end{array}$ & $6(40)$ & $8(53.3)$ & $7(46.7)$ & $8(53.3)$ \\
\hline $\begin{array}{l}>1<4 \\
(\text { Indifferent })\end{array}$ & $5(33.3)$ & $3(20)$ & $2(13.3)$ & $2(13.3)$ \\
\hline$\geq 4$ Antagonism & 0 & 0 & 0 & 0 \\
\hline
\end{tabular}

Table.3 Distribution of aminoglycoside resistance genes in resistant Acinetobacter baumannii complex

\begin{tabular}{|l|l|l|}
\hline Aminoglycoside resistance genes & Number & Percentages \\
\hline$a a c(3)-I$ & 27 & 65.8 \\
\hline $\operatorname{ant}\left(2^{\prime \prime}\right)-I a$ & 18 & 43.9 \\
\hline $\operatorname{aac}\left(6^{\prime}\right)-I h$ & 2 & 4.9 \\
\hline $\operatorname{aac}\left(6^{\prime}\right)-I b$ & 29 & 70.7 \\
\hline$a p h\left(3^{\prime}\right)-V I$ & 6 & 14.6 \\
\hline $\operatorname{armA}$ & 23 & 56.1 \\
\hline
\end{tabular}


Table.4 Aminoglycoside resistance gene profile in resistant Acinetobacter baumannii complex

\begin{tabular}{|l|c|c|c|}
\hline $\begin{array}{l}\text { Resistance gene pattern } \\
\text { (Total number) }\end{array}$ & $\begin{array}{c}\text { Aminoglycoside } \\
\text { resistance phenotype }\end{array}$ & Number & $\begin{array}{c}\text { Total } \\
\text { Number (\%) }\end{array}$ \\
\hline$a a c(3)-I$ & $\mathrm{AK}$ & 3 & 7 \\
& $\mathrm{GM}$ & 4 & $17.2)$ \\
\hline$a n t\left(2^{\prime \prime}\right)-I a$ & $\mathrm{AK}$ & 1 & $(2.4)$ \\
\hline$a a c\left(6^{\prime}\right)-I h$ & $\mathrm{GM}$ & 2 & 2 \\
& & & $(4.9)$ \\
\hline$a a c\left(6^{\prime}\right)-I b+a r m A$ & $\mathrm{GM}$ & 4 & 8 \\
& $\mathrm{AK}$ & 3 & $(19.5)$ \\
& $\mathrm{GM}+\mathrm{AK}$ & $1^{\mathbf{a}}$ & 2 \\
\hline$a p h\left(3^{\prime}\right)-I+a r m A$ & $\mathrm{GM}+\mathrm{AK}$ & $2^{\mathbf{a}}$ & $(4.9)$ \\
\hline$a a c\left(6^{\prime}\right)-I b+a a c(3)-I$ & & 2 & 4 \\
& $\mathrm{GM}$ & $2^{\mathbf{a}}$ & $(9.7)$ \\
\hline$a a c(3)-I+a a c\left(6^{\prime}\right)-I b+a n t\left(2^{\prime \prime}\right)-I a+a p h$ & $\mathrm{GM}+\mathrm{AK}$ & $4^{\mathbf{a}}$ & 4 \\
$\left(3^{\prime}\right)-V 1$ & $\mathrm{GM}+\mathrm{AK}$ & & $(9.7)$ \\
\hline$a a c(3)-I+a a c\left(6^{\prime}\right)-I b+a n t\left(2^{\prime \prime}\right)-I a+a r m A$ & & 5 & 13 \\
& $\mathrm{GM}$ & $6^{\mathbf{a}}$ & $(31.7)$ \\
\hline
\end{tabular}

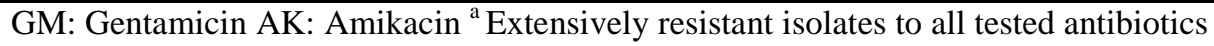

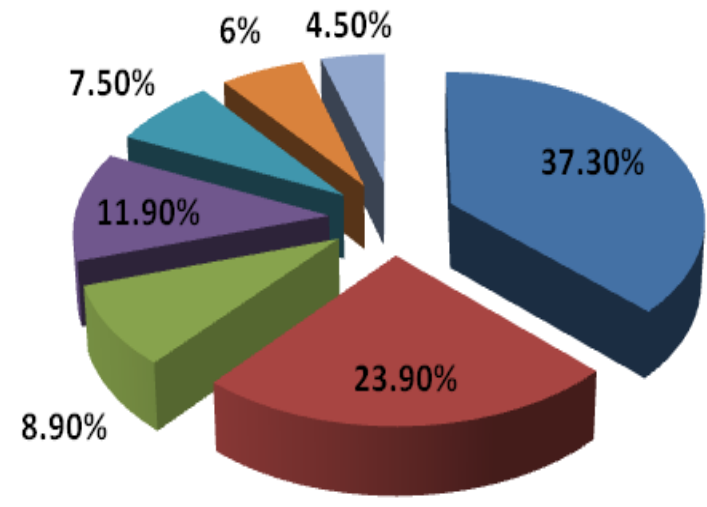

neonatal ICUs

- Pediatric ICUs

Adult medical ICUs

" Adult surgical ICUs

neuromedicin Department

- Surgical department

Medical department

Fig.1 Distribution of Acinetobacter baumannii complex in clinical departments 


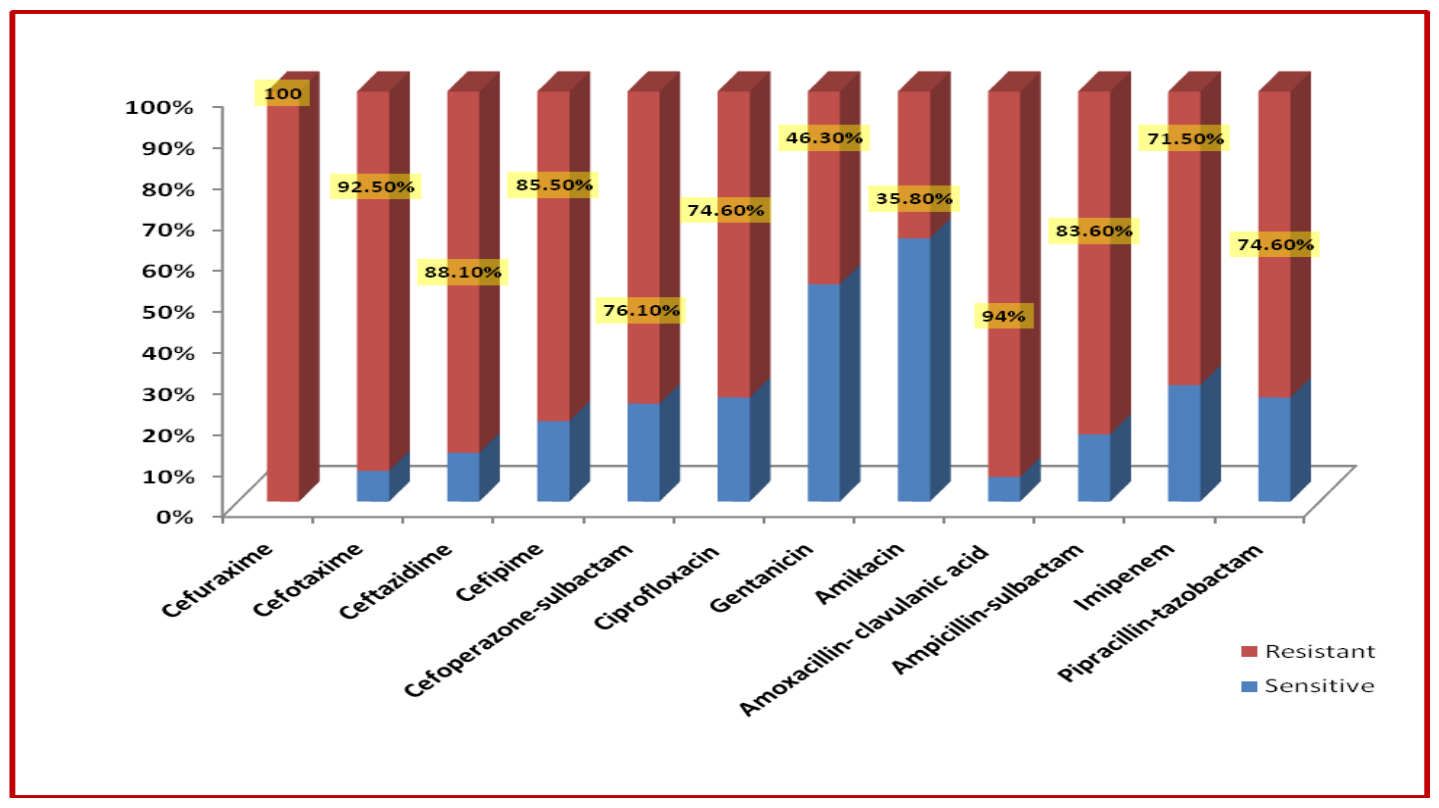

Fig.2 Antibiotic susceptibility pattern of isolated Acinetobacter baumannii complex strains

\section{Aminoglycosides resistance genes in aminoglycosides resistant $A$. baumannii complex isolates}

Several mechanisms are implicated in bacterial resistance to aminoglycosides. The most prevalent mechanisms described in species of $A$. baumannii complex are enzymatic modification of antibiotic molecule and 16S rRNA methylation (Yadegar et al., 2009; Nemec et al., 2004).

A total of 41 isolates that showed resistance to gentamicin and/or amikacin were tested for the presence of aminoglycoside modifying enzymes genes and $16 \mathrm{~S}$ RNA methylase armA gene by PCR using sets of primers as described in table (1).

All these resistant strains (41) were harboring at least one type of AME genes. Thirty-one (75.6\%) isolates carried more than one type of AMEs genes. The most frequent AMEs genes were $\mathrm{N}$-acetyltransferases (AACs); $a a c\left(6^{\prime}\right)-I b$ $(70.7 \%)$ and $\operatorname{aac}(3)-I$ (65.8\%). The least prevalent AME gene was aac $\left(6^{\prime}\right)-I h(4.9 \%)$.
Gene of $16 \mathrm{~S}$ rRNA methylase armA was detected in $56.1 \%$ table (3). The most prevalent gene profile was $\operatorname{aac}(3)-I+$ $a a c\left(6^{\prime}\right)-I b+\operatorname{ant}\left(2^{\prime \prime}\right)-I a+\operatorname{armA}$ detected in $31.7 \%$ (13/41). Co-resistance to amikacin and gentamicin were detected in 36.6\% (15/41) of aminoglycoside resistant isolates. These isolates were resistant to all tested antibiotic agents. The most prevalent gene profile in these extensively resistant strains were $\operatorname{aac}(3)-I+a a c\left(6^{\prime}\right)-I b+\operatorname{ant}\left(2^{\prime \prime}\right)-I a+a r m A$ detected in (6/15) isolates and $\operatorname{aac}(3)-I+$ $a a c\left(6^{\prime}\right)-I b+\operatorname{ant}\left(2^{\prime \prime}\right)-I a+a p h\left(3^{\prime}\right)-V 1$ detected in (4/15) isolates table (4).

This result agrees with previous results; Nemec et al., (2004), Wen et al., (2014), Sheikhalizadeh et al., (2017) and Heidary et al., (2017). Different results were obtained by Zhou et al., (2010) they found higher rate of resistance were due to $16 \mathrm{~S}$ rRNA methylase genes. This difference may be related to difference of the geographic distribution of resistant determinants.

This study has some limitation. First this 
study tested the effect of combinations in vitro only. More future studies are recommended to assess the outcome of these combinations in vivo. Second, all aminoglycosides agents were not tested. Only systemic agents recommended by CLSI (2015) for treatment of $A$. baumannii complex were tested. Lastly, other mechanisms for aminoglycosides resistance like efflux mechanism and the possible association with AMEs were not investigated. Other studies are recommended to cover these points.

In conclusion, there is an alarming increase of aminoglycosides resistance in A. baumannii complex isolated from patients with hospital acquired blood stream infections. Aminoglycosides modifying enzymes are a main mechanism associated with aminoglycosides resistance. More than one gene of aminoglycosides enzymes are present in single isolate. Combination of aminoglycosides especially amikacin with ciprofloxacin and imipenem can be used for treatment of infections with resistant isolates.

\section{References}

Brossier F, Veziris N, Aubry A, Jarlier V, Sougakoff W. Detection by Genotype MTBDRsl test of complex resistance mechanisms to second-line drugs and ethambutol in multidrug-resistant Mycobacterium tuberculosis complex isolates. J Clin Microbiol 2010; 48:1683-9.

Clinical and Laboratory Standards Institute (2015) Performance Standards for Antimicrobial Susceptibility Testing. 25th Informational Supplement, CLSI Document M100-S25, CLSI, Wayne.

Díaz PQ, Bello HT, Domínguez MY, Trabal NF, Mella SM, Zemelman RZ, González GR. Resistance to gentamicin, amikacin and ciprofloxacin among nosocomial isolates of Klebsiella pneumoniae subspecies pneumoniae producing extended spectrum betalactamases. Rev Med Chil. 2004; 132(10): 1173-8.

Gao L, Lyu Y, Li Y. Trends in Drug Resistance of Acinetobacter baumannii over a 10-year Period: Nationwide Data from the China Surveillance of Antimicrobial Resistance Program. Chin Med J (Engl). 2017; 130(6):659664.

Heidary M, Salimi Chirani A, Khoshnood S, Eslami G, Atyabi SM, Nazem H, Fazilati M, Hashemi A, Soleimani S. Molecular detection of aminoglycosidemodifying enzyme genes in Acinetobacter baumannii clinical isolates. Acta Microbiol Immunol Hung. 2017; 64(2): 143-150

Horan TC, Andrus M, Dudeck MA.CDC/NHSN Surveillance Definition of Health Care Associated Infection and Criteria for Specific Types of Infections in the Acute Care Setting. Am J Infect Control. 2008; 36(5): 309-32.

Hou PF, Chen XY, Yan GF, Wang YP, Ying CM. Study of the correlation of imipenem resistance with efflux pumps AdeABC, AdeIJK, AdeDE and AbeM in clinical isolates of Acinetobacter baumannii. Chemotherapy. 2012; 58(2): 152-8.

Kishii K, Kikuchi K, Yoshida A, Okuzumi K, Uetera $\mathrm{Y}$, Yasuhara $\mathrm{H}$, Moriya $\mathrm{K}$. Antimicrobial susceptibility profile of Acinetobacter species isolated from blood cultures in two Japanese university hospitals. Microbiol Immunol. 2014; 58(2):142-6.

Ko WC, Lee NY, Su SC, Dijkshoorn L, Vaneechoutte M, Wang LR, Yan JJ, Chang TC. Oligonucleotide-based identification of species in the Acinetobacter calcoaceticus-A. baumannii complex in isolates from 
blood cultures and antimicrobial susceptibility testing of the isolates. J Clin Microbiol. 2008 ;46(6):2052-9

Koneman EW, Allen SD, Janda WM, Schrecken-berger RC, Winn WC. Color Atlas and Textbook of Diagnostic Microbiology, 5th ed., LippincottRaven, Philadelphia; 1997 (a). Introduction to microbiology. Part II: Guidelines for the collection transport, processing analysis and reporting of culture from specific specimen sources. p. 70-121.

Lee K, Kim MN, Kim JS, Hong HL, Kang JO, Shin JH, Park YJ, Yong D, Jeong $\mathrm{SH}$, Chong Y; KONSAR Group. Further increases in carbapenem, amikacin-, and fluoroquinoloneresistant isolates of Acinetobacter spp. and $P$. aeruginosa in Korea: KONSAR study 2009. Yonsei Med J. 2011; 52(5):793-802

Lorian V (2005). Antibiotics in laboratory medicine. Philadelphia: Lippincott Williams \& Wilkins xiii, 889 p.

Magiorakos AP, Srinivasan A, Carey RB, Carmeli Y, Falagas ME, Giske CG, Harbarth S, Hindler JF, Kahlmeter G, Olsson-Liljequist B, Paterson DL, Rice LB, Stelling J, Struelens MJ, Vatopoulos A, Weber JT, Monnet DL. Multidrug-resistant, extensively drugresistant and pan drug-resistant bacteria: an international expert proposal for interim standard definitions for acquired resistance. Clin Microbiol Infect. 2012 ;18(3):268-81.

Maynard C, Fairbrother JM, Bekal S, Sanschagrin F, Levesque RC, Brousseau R, Masson L, Larivière S, Harel J. Antimicrobial resistance genes in enterotoxigenic Escherichia coli O149:K91 isolates obtained over a 23year period from pigs. Antimicrob Agents Chemother. 2003; 47: 3214-21.

Nemec A, Dolzani L, Brisse S, van den Broek
P, Dijkshoorn L. Diversity of aminoglycoside-resistance genes and their association with class 1 integrons among strains of pan-European Acinetobacter baumannii clones. J Med Microbiol. 2004; 53(Pt 12):1233-40.

Nemec A, Krizova L, Maixnerova M, van der Reijden TJ, Deschaght P, Passet V, Vaneechoutte M, Brisse S, Dijkshoorn L.Genotypic and phenotypic characterization of the Acinetobacter calcoaceticus-Acinetobacter baumannii complex with the proposal of Acinetobacter pittii sp. nov. (formerly Acinetobacter genomic species 3) and Acinetobacter nosocomialis sp. nov. (formerly, Acinetobacter genomic species 13TU). Res Microbiol. 2011;162(4): 393-404.

Nie L, Lv Y, Yuan M, Hu X, Nie T, Yang X, Li G, Pang J, Zhang J, Li C, Wang X, You X. Genetic basis of high level aminoglycoside resistance in Acinetobacter baumannii from Beijing, China Genetic basis of high level aminoglycoside resistance in Acinetobacter baumannii from Beijing, China. Acta Pharm Sin B. 2014; 4(4):295-300.

Paul M, Lador A, Grozinsky-Glasberg S, Leibovici L. Beta lactam antibiotic monotherapy versus beta lactam aminoglycoside antibiotic combination therapy for sepsis. Cochrane Database Syst Rev. 2014;1:CD003344.

Poole K. Aminoglycoside resistance in Pseudomonas aeruginosa. Antimicrob Agents Chemother 2005;49:479e87.

Potron A, Poirel L, Nordmann P. Emerging broad-spectrum resistance in Pseudomonas aeruginosa and Acinetobacter baumannii: mechanisms and epidemiology. Int $\mathbf{J}$ Antimicrob Agents 2015;45:568e85

Shaw KJ, Rather PN, Hare RS, Miller GH. Molecular-genetics of aminoglycoside 
resistance genes and familial relationships of the amino-glycosidemodifying enzymes. Microbiol Rev 1993; 57: 138-63.

Shaw KJ, Rather PN, Hare RS, Miller GH. Molecular genetics of aminoglycoside resistance genes and familial relationships of the amino-glycosidemodifying enzymes. Microbiol Rev 1993; 57: 138-63.

Sheikhalizadeh V, Hasani A, Ahangarzadeh Rezaee M, Rahmati-Yamchi M, Hasani A, Ghotaslou R, Goli HR. Comprehensive study to investigate the role of various aminoglycoside resistance mechanisms in clinical isolates of Acinetobacter baumannii. J Infect Chemother. 2017; 23(2):74-79.

Tamma PD, Cosgrove SE, Maragakis LL. Combination therapy for treatment of infections with Gram-negative bacteria. Clin Microbiol Rev. 2012; 25:450-70.

Vakulenko SB, Mobashery S. Versatility of aminoglycosides and prospects for their future. Clin Microbiol Rev. 2003; 16(3):430-50.

Van de Klundert JA, Vliegenthart JS. PCR detection of genes coding for aminoglycoside-modifing enzymes. In: Persing DH, Smith TF, Tenover FC, White TJ, editors. Diagnostic molecular epidemiology. Washington: American Society for Microbiology; 1993. p. 54752.

Wen JT, Zhou Y, Yang L, Xu Y. Multidrugresistant genes of aminoglycosidemodifying enzymes and $16 \mathrm{~S}$ rRNA methylasesin Acinetobacter baumannii strains. Genet Mol Res. 2014;

$$
\text { 13(2):3842-9. }
$$

Yadav R, Bulitta JB, Nation RL, Landersdorfer CB. Optimization of Synergistic Combination Regimens against Carbapenem- and Aminoglycoside-Resistant Clinical Pseudomonas aeruginosa Isolates via Mechanism-Based Pharmacokinetic/ Pharmacodynamic Modeling. Antimicrob Agents Chemother. 2016;61(1). pii: e01011-16.

Yadav R, Landersdorfer CB, Nation RL, Boyce JD, Bulitta JB. Novel approach to optimize synergistic carbapenem aminoglycoside combinations against carbapenem resistant Acinetobacter baumannii. Antimicrob Agents Chemother. 2015; 59(4):2286-98.

Yadegar A, Sattari M, Nour Amir M, Gholam Reza G: Prevalence of the Genes Encoding Aminoglycoside-Modifying Enzymes and Methicillin Resistance Among Clinical Isolates of Staphylococcus aureus in Tehran, Iran. Microb Drug Resist 2009, 15:109-13.

Yao J, Moellering, R. Antibacterial agents. In: Murray, P., Baron, E., Jorgensen, J., Landry, M., Pfaller, M., editors. Manual of Clinical Microbiology. American Society for Microbiology Press; Washington, DC: 2007. p. 1077-1113.

Zhou Y, Yu H, Guo Q, Xu X, Ye X, Wu S, Guo Y, Wang M. Distribution of $16 \mathrm{~S}$ rRNA methylases among different species of Gram-negative bacilli with high-level resistance to aminoglycosides. Eur J Clin Microbiol Infect Dis. 2010; 29(11):1349-53.

\section{How to cite this article:}

Ghada El-Saeed Mashaly. 2017. Aminoglycosides Resistance among Acinetobacter baumannii Complex Isolated from Hospital Acquired Blood Stream Infections. Int.J.Curr.Microbiol.App.Sci. 6(11): 1103-1112. doi: https://doi.org/10.20546/ijcmas.2017.611.130 